\title{
Dimensi Kearifan Lokal dalam Novel Laskar Pelangi
}

\author{
Hasan Suaedi \\ Universitas Muhammadiyah Jember \\ hasansuaedi@unmuhjember.ac.id \\ DOI: https://doi.org/10.32528/bb.v6i2.4953
}

First received: 23-04-2021

Final proof received: $18-10-2021$

\begin{abstract}
ABSTRAK
Kearifan lokal dapat terbentuk melalui interaksi antar individu dalam suatu masyarakat dengan lingkungan tempat tinggalnya. Kearifan lokal secara teoritis mengandung tiga dimensi utama, yaitu pengetahuan, nilai, dan kepemimpinan. Ketiga dimensi tersebut sangat penting untuk diwariskan kepada generasi muda. Pewarisan kearifan lokal dalam novel Laskar Pelangi disosialisasikan melalui orangtua dan tokoh masyarakat. Guna mengungkapkan dimensi kearifan lokal yang disosialisasikan oleh individu yang memiliki kuasa, maka peneliti menggunakan teori wacana kritis. Teori wacana kritis memnadang sebuah teks (novel) bagian dari interaksi sosial dan kebudayaan. Oleh karena itu, pengarang dalam menulis novel menginterpretasi pristiwa sosial ke dalam novelnya. Pendekatan dalam penelitian ini adalah kualitatif. Sedangkan jenis penelitian yang digunakan berupa kajian teks. Kajian teks dalam penelitian ini menggunakan model analisis data Fairlough. Luaran dalam penelitian ini adalah berupa laporan penelitian, eksplorisasi kearifan lokal, sebagai bahan pembelajaran bahasa dan sastra terutama untuk membentuk karekter peserta didik melalui budaya kearifan lokal. Dimensi kearifan lokal dalam novel Laskar Pelang diungkapkan dengan tiga dimensi. Ketiga dimensi tersebut adalah (a) dimensi pengetahuan lokal yang terdiri dari cerdas cermat sebagai media untuk meningkatkan harkat dan martabat sekolah dan pengetahuan tentang guru linguasalnya, (b) dimensi nilai lokal yang dipercaya oleh masyarakat terdiri dari nilai lokal Islam dan nilai semangat dalam menempuh pendidikan formal, (c) dimensi mekanisme pengambilan keputusan lokal yang dijalankan oleh masyarakat terdiri dari kepala sekolah sebagai pengamil keputusan dan orang pintar sebagai pengambil solusi.
\end{abstract}

Kata Kunci: kearifan lokal; dimensi; wacana kritis

\begin{abstract}
Local wisdom can be formed through interactions between individuals in a society and the environment in which they live. Local wisdom theoretically contains three main dimensions, namely knowledge, values, and leadership. These three dimensions are very important to be passed on to the younger generation. The inheritance of local wisdom in the novel Laskar Pelangi is socialized through parents and community leaders. In
\end{abstract}


order to reveal the dimensions of local wisdom that is socialized by individuals who have power, the researchers use critical discourse theory. Critical discourse theory views a text (novel) as part of social and cultural interaction. Therefore, the author in writing a novel interprets social events into his novel. The approach in this research is qualitative. While the type of research used is a text study. The text study in this study uses the Fairlough data analysis model. The outputs in this study are in the form of research reports, exploration of local wisdom, as language and literature learning materials, especially to shape the character of students through the culture of local wisdom. The dimension of local wisdom in the novel Laskar Pelang is expressed in three dimensions. The three dimensions are (a) the dimension of local knowledge which consists of being intelligent as a medium to increase the dignity of the school and knowledge of its linguistic teachers, (b) the dimension of local values that are trusted by the community, consisting of local Islamic values and values of enthusiasm in pursuing education. formal, (c) dimensions of local decision-making mechanisms run by the community consisting of principals as decision makers and smart people as solution makers.

Keywords: local wisdom; dimensions; critical discourse

\section{PENDAHULUAN}

Kearifan lokal sering kali diartikan sebagai sebuah warisan budaya. Kearifan lokal dapat terbentuk melalui interaksi antar individu dalam suatu masyarakat dengan lingkungan tempat tinggalnya. Terbentuknya kearifan lokal dalam suatu masyarakat setidaknya melibatkan tiga proses. Ketiga proses tersebut adalah pandangan hidup masyarakat, sikap, dan perilaku masyarakat dengan lingkungan dan alam. Ketiga komponen tersebut merupakan satu kesatuan yang dapat membentuk kearifan lokal suatu komunitas atau masyarakat. Artinya, suatu kearifan lokal masyarakat tertentu dapat berbeda dengan masyarakat lainnya.

Kearifan lokal yang berkaitan dengan masa depan kehidupan masyarakat menurut Suhartini (2009:1) setidaknya harus dipengaruhi oleh pengetahuan masyarakat, inovasi teknologi, permintaan pasar, pemanfaatan dan pelestarian keanekaragaman hayati dilingkungan masyarakat. Kearifan lokal secara umum memiliki tiga konsep penting. Pertama, kearifan lokal dapat dipandang sebagai pedoman bagi perilaku seseorang. Kedua, kearifan lokal tidak terlepas dari lingkungan masyarakatnya. Ketiga, kearifan lokal bersifat dinamis, lentur dan terbuka.

Maksud dari dimensi kearifan lokal dalam penelitian ini mengacu pada enam konsep teori Mitcheell (2003). Pertama, pengetahuan lokal harus mampu beradaptasi dengan lingkungan hidupnya. Artinya masyarakat harus mempunyai pengetahuan terhadap iklim dan sejumlah gejala-gejala alam. Kedua, nilai lokal setiap masyarakat memiliki nilai-nilai lokal mengenai perbuatan yang harus ditaati dan dijauhi oleh anggota masyarakatnya. Ketiga, keterampilan lokal setiap masyarakat memiliki kemampuan untuk bertahan hidup. Keempat, sumberdaya lokal setiap masyarakat dapat digunakan untuk mememenuhi kebutuhan hidupnya dan tidak dieksploitasi. Kelima, dimensi pengambilan keputusan yaitu setiap kearifan lokal memiliki petinggi atau kepala suku 
untuk memberikan keputusan-keputusan. Keenam, dimensi solidaritas kelompok lokal masyarakat. Artinya, bahwa manusia sebagai mahluk sosial tidak dapat lepas dari manusia lainnya.

Kearifan lokal yang terkandung dalam novel Laskar Pelangi perlu untuk diungkapkan. Alasan pentingnya mengungkapkan fenomena itu antara lain (1) kearifan lokal salah satu produk budaya yang perlu dilestarikan, (2) kearifan merupakan produk budaya yang perlu diwariskan kepada generasi muda, (3) kearifan lokal merupakan produk budaya yang perlu ditanamkan nilai-nilai positif kepada generasi muda, dan (4) kearifan lokal merupakan produk budaya dapat dijadikan pembelajaran untuk membentuk karakter peserta didik. Secara umum kearifan lokal yang terdapat dalam novel Laskar Pelangi berkaitan dengan tata cara berperilaku, islam sebagai pedoman hidup, nama Islami, dan pengetahuan tentang iklim dalam masyarakat Belitung. Berdasarkan fonomena di atas, mengungkapkan kearifan lokal dalam novel Laskar Pelangi penting

Berdasarkan masalah di atas, untuk mengungkapkan kearifan lokal peneliti menggunakan teori dimensi kearifan lokal. Pada penelitian ini dimensi kearifan lokal dibatasi pada tiga dimensi. Ketiga dimensi tersebut meliputi, (1) dimensi pengetahuan lokal, (2) dimensi nilai lokal dalam msyarakat, dan (3) dimensi pengambil keputusan dalam masyarakat. Pembatasan penelitian ketiga dimensi tersebut dilakukan oleh peneliti karena berdasarkan pada kemunculan data dalam novel Laskar Pelangi.

\section{METODE PENELITIAN}

Pendekatan yang digunakan dalam penelitian ini adalah pendekatan kualitatif. Penelitian ini bertujuan menemukan makna tentang dimensi kearifan loka yang terdapat dalam novel Laskar Pelangi. Dimensi kearifan lokal difokuskan pada dimensi pengetahuan lokal, dimensi nilai lokal, dan dimensi mekanisme pengambilan keputusan lokal. Penelitian ini merupakan penelitian interdisipliner/transdisipliner. Penelitian ini menggunakan teori wacana kritis, teori dimensi kearifan lokal, dan teori sosiologi sastra. Teori dimensi kearifan loka dalam penelitian ini digunakan untuk melihat dimensi pengetahuan lokal, dimensi nilai lokal, dan dimensi mekanisme pengambilan keputusan lokal. Teori sosiologi sastra digunakan untuk mengungkap fenomena-fenomena sosial dan masyarakat yang terdapat dalam novel Laskar Pelangi. Fenomena sosial dan masyarakat difokuskan untuk mengungkapkan wacana kearifan lokal yang terdapat dalam novel. Guna mengkaji interaksi sosial dan interaksi kebahasaan dalam dimensi kearifan loka, maka digunakan model analisis wacana kritis Fairclough, yaitu deskripsi, interpretasi, dan eksplanasi (1989:26).

\section{PEMBAHASAN}

\section{Dimensi Pengetahuan Lokal}

Dimensi Pengetahuan lokal dalam novel Laskar Pelangi disampaikan melalui dua dimensi pengetahuan. Kedua dimensi pengetahuan yang terdapat dalam novel Laskar Pelangi adalah cerdas cermat sebagai media meningkatkan harkat dan martabat. Guna meningkatkan harkat dan martabat sekolah $\mathrm{Bu}$ Mus mengerahkan segala upaya untuk mempersiapkan siswanya agar dapat memenangkan perlombaan cerdasa cermat. Salah 
satu cara yang dilakukan Bu Mus adalah mencari contoh-contoh soal, melatih siswa mengerjakan soal, dan membangun kepercayaan siswa-siswanya agar dapat menjawab pada saat lomba cerdas-cermat. Berikut ini pemaparan dimensi pengetahuan lokal dalam novel Laskar Pelangi.

\section{A. Cerdas Cermat sebagai Media Meningkatkan Harkat dan Martabat}

Cerdas cermat sebagai media meningkatkan harkat dan martabat sekolah dalam novel Laskar Pelangi disampaikan dengan tiga cara. Pertama, Bu Mus pontang-panting mengumpulkan soal-soal latihan untuk siswa. Kedua, Bu Mus melatih siswa mengerjakan dan menjawab soal-soal latihan. Ketiga, Bu Mus berusaha membangun kepercayaan diri siswanya agar dapat menjawab soal-soal ketika mengikuti lomba cerdas cermat. Berikut ini pemaparan cerdas cermat sebagai media meningkatkan harkat dan martabat sekolah SD Muhammadiyah Gantong.

(1)

Persoalan klasiknya adalah kepercayaan diri. Inilah problem utama jika berasal dan lingkungan marginal dan mencoba bersaing. Kami telah dipersiapkan dengan baik oleh Bu Mus. Beliau memang menaruh harapan besar pada lomba ini lebih dan beliau berharap waktu kami karnaval dulu. Bu Mus pontang-panting mengumpulkan contoh contoh soal dan bekerja sangat keras melatih kami dan pagi sampai sore. Bu Mus melihat lomba ini sebagai media yang sempurna untuk menaikkan martabat sekolah Muhammadiyah yang bertahun tahun selalu diremehkan. Bu Mus sudah bosan dihina. (LP.hlm 364)

Pada kutipan (1) modus kalimat deklaratif dan leksikalisasi digunakan untuk mengungkapkan Cerdas cermat sebagai media meningkatkan harkat dan martabat sekolah. Pada kutipan (1) Cerdas cermat sebagai media meningkatkan harkat dan martabat sekolah oleh Bu Muslimah. Pada kutipan (1) Modus kalimat deklaratif pada kutipan (1) ditandai dengan Bu Mus pontang-panting mengumpulkan contoh contoh soal dan bekerja sangat keras melatih kami dan pagi sampai sore. Pada kalimat tersebut menjelaskan bahwa Bu Muslimah mempersiapkan segala persiapan dan melatih siswanya untuk mengikuti lomba cerdas cermat. Bentuk leksikalisasi pada kutipan (1) ditandai dengan media dan menaikkan martabat. Kosakata media dan menaikkan martabat mengungkapkan tentang acara cerdas cermat yang dijadikan media oleh sekolah marjinal SD Muhammadiyah Gantong untuk meningkatkan eksistensinya sebagai sekolah Islam. Pada kutipan (1) ideologi yang disampaikan pengarang tentang sekolah Islam marjinal yang ingin menunjukkan eksistensi di dalam perlombaan cerdas cermat.

\section{B. Pengetahuan Tentang Guru Linguasalnya}

Pengetahuan tentang guru linguasalnya dalam novel Laskar Pelangi disampaikan melalui tiga cara. Ketiga cara yang digunakan dalam nove Laskar Pelangi adalah sebagai berikut. Pertama, cara mengajar tidak hanya mentransfer oelajaran, tetapi juga menjadi pembimbing spiritual. Kedua, guru yang menyuruh dan mengajarkan kepada siswanya untuk memberi sebanyak-banyaknya bukan menerima sebanyak-banyaknya. Ketiga, guru yang selalu mengajarkan tentang amar makruf nahi mungkar. Berikut ini ketiga pemaparan tentang pengetahuan tentang guru linguasalnya dalam novel Laskar Pelangi. 
Pak Harfan tampak amat bahagia menghadapi murid, tipikal "guru" yang sesungguhnya, seperti dalam linguasalnya, India, yaitu orang yang tak hanya menstranfer sebuah pelajaran, tapi juga secara pribadi menjadi sahabat dan menjadi pembimbing spiritual bagi muridnya. Beliau sering manaikturunkan intonasi, menekankan kedua ujung meja sambil mempertegas kata-kata tertentu, dan mengangkat kedua tangannya laksana orang berdoa minta hujan. (LP.hlm 23-24)

Pada kutipan (2) bentuk leksikalisasi digunakan untuk mengungkapkan pengetahuan tentang guru linguasalnya. Pada kutipan (2) pengetahuan tentang guru linguasalnya disampaikan oleh Pak Harfan. Pada kutipan (2) pengetahuan tentang guru linguasalnya terdapat dalam novel Laskar Pelangi. Bentuk leksikalisasi pada kutipan (2) ditandai dengan kokata guru yang sesungguhnya, pengajar, sahabat, dan pembimbing spiritual. Kosakata guru yang sesungguhnya menjelakan bahwa Pak Harfan adalah guru yang sebenarnya. Pada kutipan (2) pengertian guru yang sebenarnya atau sesungguhnya dicirikan dengan fungsi guru sebagai pengajar, sahabat, dan pembimbing spiritual. Pada kutipan (2) ideologi yang disampaikan pengarang tentang guru yang ideal dan guru yang sesuai dengan konsep linguasalnya.

\section{Dimensi Nilai Lokal yang Dipercaya Oleh Masyarakat}

Dimensi nilai lokal yang dipercaya oleh masyarakat dalam novel Laskar Pelangi disampaikan melalui dua dimensi nilai lokal. Kedua dimensi nilai lokal yang terdapat dalam novel Laskar Pelangi adalah nilai lokal Islam dan nilai semangat dalam menempuh pendidikan formal. Guna menanamkan nilai Islam guru dan orang tua berusaha mengajarkan nilai-nilai keislaman kepada anak-anaknya. Selain itu, nilai semangat menempuh pendidikan formal juga ditanamkan oleh orang tua untuk mewujudkan masa depan anaknya yang lebih baik. Berikut ini pemaparan dimensi lokal yang dipercaya oleh masyarakat.

\section{A. Nilai Lokal Islam}

Nilai lokal keislaman dalam novel Laskar Pelangi disampaikan melalui tiga cara. Ketiga cara yang digunakan dalam nove Laskar Pelangi adalah sebagai berikut. Pertama, guru mengajarkan kepada siswanya tentang konsep sabar. Kedua, orang tua memilihkan pendidikan formal lebih mengarah pada sekolah Islam. Ketiga, guru mengajarkan tentang konsep kepemimpinan menurut pandangan agama Islam. Berikut ini pemaparan nilai lokal keislaman dalam novel Laskar Pelangi.

(3)

"Sabarlah anakku, pertanyaanmu menyangkut pernjelasan tafsir surah Ar-Ruum dan itu adalah ilmu yang telah berusia paling tidak seribu empat ratus tahun. Tafsir baru akan kita diskusikan nanti kalau kelas dua SMP..... “

"Tak mau Ibunda, pagi ini ketika berangkat sekolah aku hampir diterkam buaya, maka aku tak punya waktu menunggu, jelaskan di sini, sekarang juga! ” (LP.hlm 110-111)

Pada kutipan (3) memunculkan nilai lokal keislaman mengajarkan makna AlQuran. Pada kutipan (3) nilai lokal keislaman mengajarkan makna Al-Quran disampaikan oleh Bu Muslimah. Pada kutipan (3) nilai lokal keislaman mengajarkan makna Al-Quran terdapat dalam novel Laskar Pelangi. Pada kutipan (3) nilai lokal keislaman mengajarkan 
makna Al-Quran diungkapkan melalui modus kalimat imperatif. Modus kalimat imperatif pada kutipan (3) ditandai dengan kosakata sabarlah anakku, jelaskan disini, dan sekarang juga. Pada kosakata sabarlah anakku, Bu Muslimah menyuruh Lintang untuk bersabar menunggu penjelasan tafsir surat Ar-Rum yang akan didapatkan di kelas 2 SMP. Kemudian pada kosakata jelaskan disini dan sekarang juga, merupakan suruhan yang diungkapkan Lintang agar Bu Muslimah menerangkan tafsir surah Ar-Rum sekarang. Pada kutipan (3) ideologi yang disampaikan pengarang tentang tafsir surah Ar-Rum yang telah berusia ratusan tahun.

\section{B. Nilai Semangat Menempuh Pendidikan Formal}

Nilai semangat menempuh pendidikan formal novel Laskar Pelangi disampaikan melalui tiga cara. Ketiga cara yang digunakan dalam nove Laskar Pelangi adalah sebagai berikut. Pertama, ayah memberikan kritikan tajam kepada Ikal dikarenakan mendapatkan nilai tidak baik pada mata pelajaran Bahasa Inggris. Kedua, keputusan orang tua untuk menyekolahkan anaknya kepada pendidikan formal guna mengubah nasih keluarganya yang selalu berada dalam garis kemiskinan. Ketiga, guru mengajarkan tentang konsep kepemimpinan menurut pandangan agama Islam. Berikut ini pemaparan nilai lokal keislaman dalam novel Laskar Pelangi.

(4)

Kecerdasannya yang lain adalah kecerdasan linguistik. Ia mudah memahami bahasa, efektif dalam berkomunikasi, memiliki nalar verbal dan logikakualitatif. Ia juga mempunyai descriptive power, yakni suatu kemampuan menggambarkan sesuatu dan mengambil contoh yang tepat. Pengalamanku dengan pelajaran bahasa Inggris di harihari pertama kelas 2 SMP nanti membuktikan hal itu. Saat itu aku mendapat kritikan tajam dari ayahku karena nilai bahasa Inggris yang tak kunjung membaik. Aku pun akhirnya menghadap pemegang kunci pintu ilmu filsafat untuk mendapat satu dua resep ajaib. Aku keluhkan kesulitanku memahami tense. (LP.hlm 115)

Pada kutipan (4) bentuk leksikalisasi dan ekspresi metafora digunakan untuk mengungkapkan nilai semangat menempuh pendidikan formal. Pada kutipan (4) nilai semangat menempuh pendidikan formal diungkapkan dengan bentuk leksikalisasi dan ekspresi metafora dikonstruksikan oleh ayah dari Ikal. Pada kutipan (4) bentuk leksikalisasi dan ekspresi metafora ditandai dengan kata kritikan tajam. Kritikan tajam mengandung makna akurat, tepat, dan mendukung. Kritikan tajam diungkapkan ayah bertujuan untuk meningkatkan nilai bahasa Inggir Ikal. Kritikan tajam juga termasuk dalam penggunakan ekspresi metafora. Pada kutipan (4) ideologi yang disampaikan pengarang tentang pentingnya kritikan dan bimbingan yang disampaikan oleh ayah kepada anaknya.

\section{Dimensi Mekanisme Pengambilan Keputusan Lokal yang Dijalankan Oleh Masyarakat}

Dimensi mekanisme pengambilan keputusan lokal yang dijalankan oleh masyarakat dalam novel Laskar Pelangi disampaikan melalui dua dimensi nilai lokal. Kedua dimensi mekanisme pengambilan keputusan lokal yang dijalankan oleh masyarakat yang terdapat dalam novel Laskar Pelangi adalah kepala sekolah sebagai pengambil keputusan dan orang pintar sebagai pemberi solusi. Keputusan yang diambil 
oleh kepala sekolah yang dijalankan oleh masyarakat berkaitan dengan penerimaan siswa baru dan rapat mengikuti lomba karnaval. Kemudian solusi yang diperoleh dari orang pintar berkaitan dengan menemukan orang yang hilang dan solusi nilai ujian sekolah agar tinggi. Berikut ini pemaparan dimensi mekanisme pengambilan keputusan lokal yang dijalankan oleh masyarakat dalam novel Laskar Pelangi.

\section{A. Kepala Sekolah sebagai Pengambil keputusan}

Kepala sekolah sebagai pengambil keputusan dalam novel Laskar Pelangi disampaikan melalui tiga cara. Ketiga cara yang digunakan dalam nove Laskar Pelangi adalah sebagai berikut. Pertama, kepala sekolah memutuskan perpanjangan waktu terhadap pembukaan penerimaan siswa baru di sekolah. Kedua, kepala sekolah memutuskan akan memberikan keputusan untuk menutup sekolah dikarenakan jumlah siswa baru tidak sesuai dengan ketentuan dinas pendidikan. Ketiga, kepala sekolah memutuskan untuk mengikuti lomba karnaval dalam acara agustusan. Berikut ini pemaparan kepala sekolah sebagai pengambil keputusan dalam dalam novel Laskar Pelangi.

(5)

Tahun lalu SD Muhammadiyah hanya mendapatkan sebelas siswa, dan tahun ini Pak Harfan pesimis dapat memenuhi target sepuluh. Maka diam-diam beliau telah mempersiapkan sebuah pidato pembubaran sekolah di depan para orangtua murid pada kesempatan pagi ini. Kenyataan bahwa beliau hanya memerlukan satu siswa lagi untuk memenuhi target itu menyebabkan pidato ini akan menjadi sesuatu yang menyakitkan hati.

"Kita tunggu sampai pukul sebelas," kata Pak Harfan pada Bu Mus dan seluruh orangtua yang telah pasrah. Suasana hening. (LP.hlm 5)

Pada kutipan (5) bentuk leksikalisasi digunakan untuk mengungkapkan kepala sekolah sebagai pengambil keputusan. Pada kutipan (5) kepala sekolah sebagai pengambil keputusan yang terdapat dalam novel Laskar Pelangi. Pada kutipan (5) leksikalisasi ditandai dengan kosakata pesimis, pidato, dan satu siswa lagi. Kosakata pesimis mengandung makna gambaran yang dirasakan Pak Harfan berupa perasaan murung, sedih, tidak yakin, dan putus asa. Pak Harfan sudah merasa tidak yakin akan memenuhi target sepuluh orang untuk siswa baru. Oleh karena itu, Pak Harfan menyiapkan pidato untuk memberitahukan kepada wali murid bahwa sekolah Muhammadiyah akan dibubarkan. Penyebab dibubarkannya sekolah karena target sepuluh orang siswa baru tidak tercapai. Pada kutipan (5) ideologi yang disampaikan pengarang tentang sikap pesimis pak Harfan untuk memenuhi target sepuluh siswa baru. Selain itu, pengarang juga mengungkapkan tentang sekolah yang akan dibubarkan karena kekurangan jumlah siswa yang mendaftar.

\section{B. Orang Pintar sebagai Pemberi Solusi}

Orang pintar sebagai pemberi solusi dalam novel Laskar Pelangi disampaikan melalui tiga cara. Ketiga cara yang digunakan dalam nove Laskar Pelangi adalah sebagai berikut. Pertama, memberikan solusi untuk menghadapi ujian sekolah agar lancar dan mendapatkan nilai tinggi. Kedua, Ikal dan Flo membaca solusi yang diberikan oleh Tuk 
Bayan Tula dengan membuka gulungan kertasnya. Ketiga, Tuk Bayan Tula dijadikan solusi untuk mencari keberadaan Flo yang telah lama hilang di dalam hutan. Berikut ini pemaparan orang pintar sebagai pemberi solusi dalam dalam novel Laskar Pelangi.

(6)

Tuk mengangkat gulungan kertas pesannya tinggi-tinggi seakan mengatakan, 'Lihatlah wahai manusia-manusia cacing tak berguna, siapa pun, kasat atau siluman tak 'kan sanggup melawanku. Aku telah membinasakan iblis-iblis dan dasar neraka untuk membuat keajaiban yang membalikkan hukum alam. Nilai-nilai ujianmu akan melingkar sendiri dalam kegelapan untuk menyelamatkanmu di sekolah tua itu. Terimalah hadiahmu, karena engkau anak muda pemberani yang telah menantang maut untuk menemuiku ...." (LP. hlm 420)

Pada kutipan (6) bentuk ketransitifan tipe tindakan dan tindak asertif digunakan untuk mengungkapkan konstruksi mampu memberikan solusi dari permasalahan. Pada kutipan (6) konstruksi mampu memberikan solusi dari permasalahan dikonstruksikan oleh Tuk Bayan Tula. Konstruksi mampu memberikan solusi dari permasalahan terdapat dalam novel Laskar Pelangi. Bentuk ketransitifan tipe tindakan ditandai dengan Tuk mengangkat gulungan kertas. Tuk adalag subjek yang melakukan tindakan mengangkat sebuah objek berupa gulungan kertas. Bentuk tindak asertif pada kutipan (6) ditandai dengan nilai-nilai ujianmu akan melingkar sendiri dalam kegelapan untuk menyelamatkanmu di sekolah tua itu. Terimalah hadiahmu, karena engkau anak muda pemberani yang telah menantang maut untuk menemuiku. Pada kalimat tersebut Tuk Bayan menyatakan bahwa nilai Mahar dan Flo akan melingkar sendiri dalam kegelapan, sehingga Mahar dan Flo dapat lulus sekolah. Pada kutipan (6) ideologi yang disampaikan tentang kepercayaan terhadap orang sakti dapat memberikan solusi dari masalah.

\section{SIMPULAN}

Dimensi kearifan lokal dalam novel Laskar Pelang diungkapkan dengan tiga dimensi. Ketiga dimensi tersebut adalah (a) dimensi pengetahuan lokal yang terdiri dari cerdas cermat sebagai media untuk meningkatkan harkat dan martabat sekolah dan pengetahuan tentang guru linguasalnya, (b) dimensi nilai lokal yang dipercaya oleh masyarakat terdiri dari nilai lokal Islam dan nilai semangat dalam menempuh pendidikan formal, (c) dimensi mekanisme pengambilan keputusan lokal yang dijalankan oleh masyarakat terdiri dari kepala sekolah sebagai pengamil keputusan dan orang pintar sebagai pengambil solusi.

Ketiga dimensi nilai kearifan lokal dalam novel Laskar Pelangi disampaikan pengarang melalui Sembilan fitur lingual. Kesimbilan fitur lingual yang digunakan antara lain (1) leksikalisasi, (2) klasifikasi, (3) metafora, (4) kalimat deklaratif, (5) kalimat imperatif, (6) eufimisme, (7) ketransitifan tipe tindakan, (8) tindak direktif, dan (9) tindak asertif.

\section{REFERENSI}

Sedyawati, E. (2006). Budaya Indonesia (Kajian Arkeologi, Seni, dan Sejarah). Jakarta: PT. Raja Grafindo Persada.

Endraswara, S. (2012). Teori Pengkajian Sosiologi Sastra. Yogyakarta: UNY Press 
Eriyanto. (2005). Analisis Wacana: Pengantar Analisis Teks Media. Yogyakarta: LkiS

Fairclough, N. (1989). Language and Power. London: Longman.

Fauzan, U. (2014). Analisis Wacana Kritis dari Model Fairclough Hingga Mills. Jurnal Pendidik, 6 (1), https://www.academia.edu/13372775/.

Fuadi, A. (2009). Negeri 5 Menara. Jakarta: Gramedia.

Geertz. (2007). Local Wisdom in Education. Journal of Education. .http://www. ied.edu.hk/cric/

Halliday M.A.K, \& Hasan R. (1992). Bahasa, Konteks, dan Teks: Aspek-aspek Bahasa dalam Pandangan Semiotika Sosial. Terjemahan Asruddin Barori Tou. Yogyakarta: gadjah Mada University Press. 1980.

Harmoni. (2010). Jurnal Multikultural dan Multireligius, volume IX nomor 34, Puslitbang Kehidupan keagamaan Badan Litbang. Jakarta

Hirata, A. (2015). Laskar Pelangi. Bandung: PT Bentang Pustaka

Kriyantono, R. (2014).Teori Public Relations Perspektif Barat Dan Lokal: Aplikasi Penelitian dan Praktik. Jakarta: Kencana.

Kuncoro B, Sanie. (2014). MaYan. Bandung: PT Bentang Pustaka

Mitchell. (2003). Kearifan Lokal dalam Perspektif Budaya Sunda. Bandung: Kiblat Buku Utama.

Nurgiyantoro, B. (2010). Teori Pengkajian Fiksi. Yogyakarta: Gadjah Mada University Press

Santoso, A. (2006). Bahasa, Masyarakat, dan Kuasa: Topik-topik Kritis dalam Kajian Ilmu Bahasa. Malang: Lembaga Pengembangan Pendidikan dan Pembelajaran (LP3)

Santoso, A. (2012). Studi Bahasa Kritis, Menguak Bahasa Membongkar Kuasa. Bandung: Mandar Maju.

Sayuti, S. (2017). Berkenalan dengan Prosa Fiksi. Yogyakarta: Cantrik Pustaka.

Somadayo, S. (2011). Strategi dan Tehnik Pembelajaran Membaca. Yogyakarta : Graha Ilmu 
Suhartini. (2009). Kajian Kearifan Lokal Masyarakat dalam Pengelolaan Sumberdaya Alam dan Lingkungan. http://staff.uny.ac.id

Sumardjo, J. (1999). Konteks Sosial Novel Indonesia 1920-1977. Bandung: Alumni

Tarigan, H. G. (1986). Prinsip-Prinsip Dasar Sastra. Bandung: Angkasa

Tarigan, H. G. (1995). Dasar-Dasar Psikosastra. Bandung: Angkasa.

Teeuw, A. (2003). Sastra dan Ilmu Sastra,Pengantar Teori Sastra. Jakarta: Pustaka Jaya.

Van Dijk, T. A. (1995). Discourse Analysis as Ideology Analysis. Dalam Christina Schoaffner and Anita L(Ed). Language and Pace (17³3). USA: Dartmouth.

Van Dijk, T. A. (2006). Ideology and Discourse Analysis. Journal Political Ideologies, 11 (2), http://www.discourses.org.

Wagiran. (2012). Pengembangan Karakter Berbasis Kearifan Lokal Hamemayu Hayuning Bawana (Identifikasi Nilai-nilai Karakter Berbasis Budaya).Yogyakarta: Universitas Negeri Yogyakarta.

Wellek, R., \& Warren, A. (2016). Teori Kesusasteraan. Jakarta: Gramedia. 